DOI 10.20396/temáticas.v1i1/2.11212

\title{
LUKÁCS E O MARXISMO \\ CONTEMPORÂNEO
}

Sérgio Lessa

Sob a enorme pressão da evolução histórica, da chamada "sobrevida" do capital no mundo contemporâneo, de um lado e, de outro, da carência de acúmulo teórico que possibilite a compreensão dos nexos e das conexões da forma de ser da sociabilidade contemporânea, o marxismo no século XX deu origem a três vertentes fundamentais: 1) o marxismo estruturalista (composto não apenas pelo marxismo vulgar, mas também por elaborações teóricas sofisticadas, como as de Althusser e Cohen), que realiza, ao menos em parte, um retorno às concepções ontológicas materialista-mecanicistas; 2) o idealismo marxista, que postula o deslocamento e substituição do trabalho, enquanto categoria fundante do ser social, pela linguagem, pelos valores, etc. Pensamos, fundamentalmente, na Escola de Frankfurt; e 3) o marxismo ontológico, que busca em Marx os elementos de uma ontologia do mundo dos homens.

Sinteticamente, passaremos à análise de cada uma destas vertentes.

Temáticas, Campinas, 1(1/2):95-127, jul./dez. 1993. 


\section{O Marxismo Estruturalista e Alguns dos seus Desdo- BRAMENTOS}

Das três vertentes, o marxismo estruturalista foi o que maior influência exerceu ao longo deste século. Se caracteriza, èn primeiro lugar, por compreender a reprodução e a produção no sentido restrito e exclusivo de "práticas econômicas de produção". ${ }^{1}$ Esta limitação da produção e reprodução social enquanto momento meramente econômico está associada à disjunção entre o "materialismo histórico e o dialético", tão característico deste universo teórico, e à construção de um fosso entre a esfera econômica e a subjetividade humana que, também caracteristicamente, é superado pela postulação de uma relação de determinação mecânica do pensado pelo objetivado.

Paradigmático, nesse universo teórico, são as considerações de Louis Althusser em "De El Capital a la filosofía de Marx", texto que serviu de prefácio de Para leer El Capital.

Argumenta Althusser que,

(...) Marx só pôde chegar a ser Marx fundando uma teoria da história e uma filosofia da distinção histórica entre a ideolo-gia e a ciência e, em última análise, a que essa fundação se tenha consumado na dissipação do mito religioso da leitura [presente no jovem Marx]. Ali onde o jovem Marx dos Manuscritos de 1844 lia a livro aberto, imediatamente (grifo nosso-SL), a essência humana na transparência de sua alienação, $O$ Capital toma, pelo contrário, a exata medida de uma distância, de um deslocamento interior do real, ambos inscritos em sua estrutura, e de tal modo que tornam ilegiveis seus próprios efeitos e fazem da ilusão de sua leitura imediata o último $e$ o ápice dos seus efeitos: o fetichismo. (...) descobrindo que a verdade da história não se lê em seu discurso manifesto, porque o texto da história não é um texto

${ }^{1}$ BALIBAR, E., Sur les concepts fondamentaux du materialisme historique, Maspero, p. 189.

Temáticas, Campinas, 1(1/2):95-126, jul./dez. 1993. 
no qual fale uma voz (o Logos), mas a anotação inaudivel e ilegivel dos efeitos de uma estrutura de estruturas". ${ }^{2}$

Descoberto o caráter "religioso" da "leitura" do real pelo jovem Marx e, se apoiando no próprio Marx da "maturidade", fundamentalmente no Marx de $O$ Capital, argumenta Althusser que objeto real e objeto do conhecimento são duas coisas distintas e que, portanto, o objeto de que trata a teoria não é o objeto real, mas o objeto do conhecimento.

Analogamente a como, anteriormente, fora inserida a imediaticidade religiosa na relação entre sujeito/objeto no jovem Marx, agora a distinção entre sujeito e objeto é posta como uma distinção "absoluta", o que permite a Althusser postular que "o processo de produção do objeto do conhecimento ocorre por completo no conhecimento (...)" (47. Cf. tb. pg. 40).

Ora, se o objeto do conhecimento é produção exclusiva da subjetividade, do pensamento, terminamos no puro idealismo? A saída de Althusser, após afirmar a absoluta distinção entre objetividade e subjetividade, é postular que o pensamento não é pura subjetividade.

“Quando Marx nos diz que o processo de produção do conhecimento (...) ocorre por completo no conhecimento, na 'cabeça' ou no pensamento, não cai, nem por um segundo, em um idealismo da consciência (...) Este pensamento é o sistema historicamente constituido de um aparato de pensamento, baseado e articulado na realidade natural e social. $O$ pensamento é definido pelo sistema das condições reais que fazem dele (...) um modo de produção determinado de conhecimentos." (47 e ss.)

${ }^{2}$ ALThUSSER, L. e BALIBAR, E. Para leer El Capital, Siglo XXI, Argentina, 1973, pg. 21-2. As citações serão feitas ao longo do texto, com o número das páginas entre parênteses, até indicação em contrário.

Temáticas, Campinas, 1(1/2):95-126, jul./dez. 1993. 
Em outras palavras, para Althusser, o objeto do conhecimento é produto exclusivo do pensamento desde que, por pensamento, compreendamos toda a malha real que articula subjetividade e individualidade. Há uma subjetividade que é absolutamente distinta do mundo objetivo, e há o pensamento que é definido pelas "condições reais". Que subjetividade é essa que não é pensamento Althusser não esclarece! Com o que ficamos com uma estrutura conceitual problemática: uma subjetividade que é, ao mesmo tempo, "absolutamente" distinta do real ( e tão distinta que, o que conhecemos, não é o real, mas o "objeto do conhecimento") e "definida" pelas "condições reais". (47-8)

Todavia, será esta estrutura conceitual a base para próximo passo de Althusser: mostrar que o real, a "realidade natural e social" na qual se baseia o "aparato de pensamento", funciona como uma matéria-prima que é historicamente condicionada, socialmente construída: "há uma grande distância entre, por exemplo, a matériaprima que trabalhou Aristóteles e a matéria-prima que trabalharam Galileu, Newton ou Einstein (...)" (48-9).

"O conhecimento, ao trabalhar sobre seu 'objeto', não trabalha, pois, sobre o objeto real, mas sobre sua própria matériaprima, que constitui - no sentido rigoroso do termo - seu objeto (de conhecimento) que é, desde as formas mais rudimentares do conhecimento, distinto do objeto real (...)." (49)

Instaurada esta distinção "absoluta" entre o conhecimento e a coisa-em-si, o método em Althusser passa a ter como nódulo essencial a busca de um "conceito" que confira direção e sentido à reflexão (pgs. 49-52). Caracteristicamente, o estruturalismo althusseriano efetiva um retorno ao kantismo. De modo igualmente característico, reduz a individualidade a agente de um aparato de pensamento que é definido pelo complexo de relações sociais que determina o modo de produção de conhecimentos. Misteriosamente, a objetividade é inacessível à ideação, e a subjetividade é reduzida a determinações

Temáticas, Campinas, 1(1/2):95-126, jul./dez. 1993. 
sócio-genéricas materiais. Essa dupla redução caracteriza o eștruturalismo althusseriano.

Com a démarche althusseriana está perdida a unidade intrínseca da obra de Marx. Esta tem que ser reinterpretada para ser elevada à ciência. Toda a problemática do corte epistemológico faz sua entrada em cena. Do mesmo modo, "o conceito de história" se transforma numa questão dramática, pois como explicá-la se as ações humanas, que sempre contêm elementos volitivos, valorativos, teleológicos, são meros reflexos mecânicos, suportes ou decorrências, do movimento objetivo das estruturas?

Nos anos 1970/80 o marxismo estruturalista entra em profunda crise. Novas correntes de pensamento não-marxistas se desenvolvem e colocam problemas, normalmente centrados sobre os fenomenos da subjetividade humana, que o marxismo estruturalista não consegue enfrentar com sucesso. Ao mesmo tempo, no interior do próprio marxismo, se desenvolvem críticas severas ao caráter mecanicista e ingenuamente materialista do marxismo estruturalista. Significativa do alcance e debilidades dessas críticas são as considerações do historiador inglês E. P. Thompson, ${ }^{3}$ que considera Althusser a elevação do stalinismo a uma inédita sofisticação teórica que, no fundo, seria de matiz idealista. Se insurge Thompson, acima de tudo, contra a negação althusseriana do papel ativo dos homens na história.

\section{I.1 O "Marxismo Analítico"}

A crise do althusserianismo teve uma curiosa conseqüência no desenvolvimento do marxismo estruturalista, principalmente nos países de língua inglesa: levou ao extremo a sua tendência ao formalismo lógico-abstrato. A mais acabada expressão desta tendência é o Marxismo Analítico.

${ }^{3}$ THOMPSON,E. P., The poverty of theory and other essays, Monthly Review Press, 1978.

Temáticas, Campinas, 1(1/2):95-126, jul./dez. 1993. 
Muitos dos marxistas analíticos, entre os quais Roemer e Elster, reconhecem em Gabriel Cohen ${ }^{4}$ o fundador dessa nova vertente do pensamento marxista. ${ }^{5}$

A démarche de Cohen é curiosa. Tem início pela busca de um paralelo entre a história em Hegel e em Marx, mas de tal maneira que Marx se transforma num hegeliano materialista. O espirito se transubstancia em classe operária, a identidade sujeito-objeto no comunismo, o tempo hegeliano no tempo da luta de classes de Marx. Deste ponto de partida, Cohen evolui rapidamente para, a partir do conhecido prefácio à Crítica da economia política, afirmar que:

“A estrutura econômica (ou 'base real') é (...) composta das relações de produção. Nada mais é dito [por Marx] que participe da sua composição. Nós concluímos, ex silentio, que apenas as relações de produção servem como constituintes da estrutura econômica. Isto significa que as forças produtivas não são parte da estrutura econômica." (28)

A análise de Cohen, a partir de então, tem que excluir força de trabalho da categoria de forças produtivas (32/3), caracterizar as estruturas a partir das relações de propriedade (35/6); "corrigir" Marx no sentido de substituir "sociedade" por "estrutura social" (37) e afirmar que a estrutura economica é "forma", presumivelmente por oposição a "conteúdo"(37). O que nos interessa mais de perto, nesta investigação, no entanto, é o caráter da oposição que Cohen afirma existir entre o "material" e o "social", pelo qual "Nem todas as relações entre os homens são sociais" ("Not all relations between men are social") (93), mas derivadas do mundo material. $\mathrm{E}$, o que se segue com absoluta necessidade, Cohen postula a possibilidade de uma descrição do mundo material "neutra", "da qual não podemos deduzir sua forma social". Que de uma descrição da

${ }^{4}$ Cohen, G., Karl Marx's theory of history - a defense, USA, 1978. As citações desta obra de Cohen serão feitas no próprio texto, o número da página entre parênteses, até indicação em contrário.

${ }^{5}$ Cf., por exemplo, o artigo de Thomas F. Mayer, op. cit., p. 418.

Temáticas, Campinas, 1(1/2):95-126, jul./dez. 1993. 
natureza não podemos "deduzir" o ser social, não há dúvida; mas que tal descrição possa ser neutra, não-social no dizer de Cohen, corresponde à afirmação da neutralidade das ciências naturais, posição esta muito mais próxima ao positivismo que à tradição marxista. (94)

Este tipo de "rigor analítico" postulado por Cohen é considerado, no artigo de Mayer acima citado, como momento fundante do Marxismo Analítico. Todavia, o traço mais característico ${ }^{6}$ desta nova tendência, a nosso ver, está no individualismo metodológico, assim exposto por Elster: ${ }^{7}$

"todos os fenômenos sociais - suas estruturas e suas mudanças - são por princípio explicáveis por métodos (ways) que apenas envolvam indivíduos - suas propriedades, suas finalidades, suas crenças e suas ações. $O$ individualismo metodológico assim concebido é uma forma de reducionismo".

Com o marxismo analítico, a dissociação entre a esfera econômico-material e a esfera da subjetividade humana, traço característico do marxismo estruturalista, terminou por levar a uma outra dissociação, não menos grave nas suas conseqüências: a dissociação entre individualidade e sociabilidade. Como a individualidade não é tomada no seu processo histórico-genético, se converte em algo dado, cuja fundação e desenvolvimento não se constituem em problema. A forma e o conteúdo que assume esta dissociação, no Marxismo Analítico implica num retorno ao postulado clássico do pensamento

${ }^{6}$ Mesmo quando autores que se alinham com o Marxismo Analítico recusam o individualismo metodológico, eles o fazem em termos tais que significam apenas a aceitação diferenciada dos postulados do individualismo metodológico. Cf, por exemplo, Mayer, op. cit., pp. 426 e ss.

${ }^{7}$ ELSTER, J., Making sense of Marx, Cambridge University Press, Cambridge, 1985, pg. 5 .

Temáticas, Campinas, 1(1/2):95-126, jul./dez. 1993. 
moderno, de Hobbes a Rousseau: a sociabilidade é o resultado das ações de indivíduos cuja individualidade não é constituída através de complexas mediações sócio-genéricas, mas é dada de uma forma a-histórica, ${ }^{8}$ por uma natureza humana que permanece intocável ao longo da história e que corresponderia à essência humana. Significa, também, um retorno ao pressuposto básico da economia política burguesa: o elemento fundante da economia seriam as açōes de indivíduos "racionais" por natureza. Esta é a forma concreta que assume a peculiar recusa da categoria da totalidade pelo marxismo analítico.

Esse retorno ao "indivíduo-mônada" 9 permite a Elster a aplicação da teoria dos jogos na análise dos fenômenos sociais. ${ }^{10}$ Sem nos estendermos na sua refutação, apenas assinalaremos que a teoria dos jogos pressupõe uma estabilidade das regras e dos padrões de escolha (ditas "racionais") por parte dos indivíduos que é, ontologicamente, incompatível com a dinâmica peculiar à reprodução social. Tal teoria, antes de ser "marxista", como querem Elster e Mayer, se encontra por inteiro no interior da concepção de mundo

${ }^{8}$ ELSTER argumentaria, contra essa nossa afirmação, que pressupor "egoísmo" ou "racionalidade" na esfera da ação individual é "baseada em considerações puramente metodológicas, e não em qualquer consideração acerca da natureza humana". (6) Todavia, esta consideração metodológica ganha acentos ontológicos quando utilizada para "explicar" a processualidade social, já que, para Elster, “Explicar é oferecer o mecanismo (...) que articula o singular ao universal." (5) Em Marx Hoje (Paz e Terra, 1989 , pg. 37) reconhece que “(..) o suposto de que os indivíduos sejam racionais e egoístas não faz parte da doutrina, embora seja compativel com ela".

${ }^{9}$ MARX, K., A questão judaica, Ed. Moraes, s/d, pp. 13-52.

${ }^{10} \mathrm{Cf}$. ELSTER, J,. Marx hoje, op. cit. pp. 43-5. O exemplo dado por Elster, que demonstra a impossibilidade lógica, a partir dos pressupostos por ele escolhidos, de uma greve, é um falso silogismo muito mais que um paradoxo. Demonstra claramente a incapacidade desse arcabouço teórico em explicar até fenômenos sociais que não são dos mais complexos, como uma greve.

Temáticas, Campinas, 1(1/2):95-126, jul./dez. 1993. 
tipicamente cartesiana do individualismo metodológico: o todo é formado pela justaposição das partes, o complexo é a justaposição do simples. ${ }^{11}$

Ainda que apresentando novidades, que fazem com que a crítica ao althusserianismo não dê conta das especificidades do marxismo analítico, no limitado espaço deste artigo, gostaríamos de chamar atenção ao fato de a dissociação individualidade/sociabilidade característica dos escritos de Elster, Roemer, etc., exibir uma continuidade com a dicotomia indivíduo/história, subjetividade/estruturas objetivas, encontradas em Althusser. E o elo que articula estes dois níveis de dicotomias é a obra de Cohen. Nesse sentido, é curioso e significativo o entusiasmo que Cohen exibe pelos primeiros escritos de Althusser e sua decepção com os livros posteriores. ${ }^{12}$

Essa migração para o individualismo burguês conduz à reavaliação da exploração dos homens pelos homens. Tanto Roemer ${ }^{13}$ como Elster ${ }^{14}$ terminam, cada um a sua maneira, por afirmar que a questão da exploração do homem pelo homem não é meramente moral, e que portanto deve ser tratada como o que de fato é: um problema econômico. ${ }^{15}$ A questão então, se colocaria da seguinte maneira: há uma melhor forma de relacionamento possível entre

${ }^{11}$ Cf. ELSTER, J., Making Sense ..., op. cit., pgs. 14-5. E tb. Mayer, op. cit.. "De acordo com o individualismo metodológico, (...) quaisquer 'leis de movimento e auto-regulação' do capitalismo devem ser deduzidas como teoremas de axiomas que especifiquem os motivos e limitações de firmas, trabalhadores e consumidores." (ELSTER, Marx hoje, op. cit., pg. $38)$.

${ }^{12} \mathrm{COHEN}$, op. cit., pp. X-XI.

${ }^{13}$ ROEMER, J. E., A general theory of exploitation and class, Cambridge, Massachussetts, 1982. E, do mesmo autor, Free to Lose: An Introduction to Marxist Economic Philosophy, Massachussetts Harvard University Press, Cambridge, 1988.

${ }^{14}$ ELSTER, J., Making sense of Marx, op. cit. pp. 216-233.

${ }^{15} \mathrm{Nas}$ palavras de Elster: “(..) a exploração não é um conceito moral fundamental. A exploração, quando censurável, o é por causa das características específicas da situação (...)”, (Marx hoje, op. cit., p. 116).

Temáticas, Campinas, 1(1/2):95-126, jul./dez. 1993. 
os homens que o relacionamento baseado na exploração? Se houver um outro relacionamento não baseado na exploração e que seja - realçamos.- possível, então a exploração é condenável. Caso contrário, ser explorado pode ser a melhor alternativa, tanto para o explorado quanto para o explorador. Nesse caso a exploração poderia se basear numa relação de troca livre e voluntária. ${ }^{16}$

Em artigos da Science and Society, Anderson e Thompson e Mayer, ${ }^{17}$ debatido exaustivamente este aspecto da questão, e não valeria a pena, agora, nos determos sobre os detalhes deste debate. Esperamos, contudo, com os elementos aqui apresentados, ter garantida, ao menos, a legitimidade da postulação da nossa hipótese acerca da evolução do marxismo estruturalista. Essencialmente, de que o esgotamento da vertente althusseriana tem alguma repercussão no desenvolvimento posterior do autodenominado Marxismo Analítico. Tal como, a nosso ver, a epistemologia althusseriana possui uma fundamentação kantiana, o Marxismo Analítico exibe um forte parentesco com o pensamento liberal. Entre um e outro, apesar das diferenças que não devem nem podem ser desprezadas repetimos que a crítica de um não esgota a crítica do outro - pensamos haver elementos de continuidade cujo elo articulatório principal possivelmente seriam as teorizaçōes de Gabriel Cohen.

Em suma, para efeito deste trabalho, caracterizaríamos este primeiro conjunto de formulações teóricas que iriam do marxismo vulgar ao marxismo analítico, passando por Althusser, por:

1) conceber a substancialidade humana enquanto dualidade dicotômica composta por uma instância material-objetiva e uma esfera da subjetividade. A relação entre estas duas instâncias se daria tanto pela determinação unilateral da consciência pelas estruturas (Althusser) como também pela inversão simétrica desta deter-

${ }^{16}$ ELSTER, J., idem, p. 98 e ss.

${ }^{17}$ ANDERSON, W.H.L, THOMPSON, F.W., "Neoclassical Marxism", in Science and Society, 52:2, 1988. Mayer, T. F. "In defense of Analytical Marxism", in Science and Society, 53:4, 1989-90.

Temáticas, Campinas, 1(1/2):95-126, jul./dez. 1993. 
minação. A teoria dos jogos, a escolha racional e o individualismo metodológico seriam formas diversas de apresentação dessa dicotomia entre estrutura e subjetividade;

2) disjuntar esfera econômica e totalidade social, quer conferindo-lhes um caráter de exterioridade estrutural(Althusser), quer conferindo às forças produtivas uma materialidade distinta da social (como o faz Cohen), quer desconsiderando a problemática conexa à afirmação marxiana da predominância da esfera econômica na determinação da reprodução social (Marxismo Analítico);

2a) esta disjunção, ao não conseguir dar conta dos complexos processos que articulam subjetividade e objetividade no mundo dos homens, termina por afirmar, ao mesmo tempo, a radical separação destas duas esferas e, no caso de Althusser e Balibar, uma relação mecânica entre elas; em Cohen, esta disjunção assume a forma de uma contraposição entre o material e o social; e, no marxismo analítico, esta disjunção é potencializada pelo individualismo metodológico;

2b) esta disjunção está associada a uma postulação metodológica de fundo: a necessidade de um construto teórico prévio que ordenará a realidade em objetos e conhecimentos científicos. Em se tratando do conjunto formado por Althusser e Balibar, esta necessidade metodológica possui acentos claramente kantianos. No caso do Marxismo Analítico, este modelo teórico a priori se limita a admissão inconfessa da pressuposição da existência de uma natureza humana a-histórica;

2c) esta disjunção, ainda, implica em compreender a história como o movimento das estruturas, movimento do qual a esfera da subjetividade é mera decorrência. Os indivíduos e as açōes humanas não são mais os elementos fundantes do ser social, mas sim Träger, suportes, dos movimentos estruturais. No Marxismo Analítico, esta determinação mecânica da subjetividade pela base material deu origem, numa aparente inversão crítica, ao individualismo meto-

Temáticas, Campinas, 1(1/2):95-126, jul./dez. 1993. 
dológico. Se, no primeiro momento, as estruturas determinavam as individualidades, agora são as ações imediatas dos indivíduos o único momento fundante do ser social;

$2 \mathrm{~d})$ a teoria dos jogos e a escolha racional ${ }^{18}$ são resultados imediatos desta cisão entre sociabilidade e individualidade. Nessas teorias, tal como em Althusser, os indivíduos são Träger das estruturas. Aqui a aparência da inversão que mencionamos em 2c) se evidencia por completo;

3) a crise da vertente do marxismo representada por este primeiro conjunto de autores assume a forma de uma especialização formalista dos conceitos que atinge níveis elevados de esterilidade (Balibar, mais que Althusser, de um lado, e Cohen e o marxismo analítico de outro) à medida em que são discussões que se propõem puramente lógicas, que não tomam o real como esfera resolutiva das elaborações teóricas.

\section{O IDEALISMo MarXista}

$\mathrm{Na}$ raiz do idealismo marxista estão o jovem Lukács, de História e consciência de classe e a Escola de Frankfurt. ${ }^{19}$ O que marca a primeira grande obra do filósofo húngaro é a identidade entre sujeito e objeto na construção da ordem comunista. Daí a sua disjunção, estranhamente hoje bastante citada, entre o método e o conteúdo do

${ }^{18}$ Cf. ELSTER, J., Marx hoje, op. cit., pp. 40-1, onde é exposta a relação entre teoria dos jogos e escolha racional.

${ }^{19} \mathrm{~A}$ relação entre Lukács, Korsch e a primeira Escola de Frankfurt é bastante conhecida. Por isso nos limitaremos, aqui, a esta referência genérica, remetendo a três títulos que exploram de perspectivas distintas esta relação: Jay, M., La imaginación dialéctica, Ed. Taurus, 1974, Madrid e Arato, A. e Breines, P., El jóven Lukács e los origenes del marxismo occidental, Fondo de Cultura Económico, México, 1986. Löwy, M., Para uma sociologia dos intelectuais revolucionários. Liv. Ed. Ciências Humanas, São Paulo, 1979. 
pensamento marxiano. Estas posições seriam mais tarde rejeitadas pelo autor como "idealistas" e "hegelianas". ${ }^{20}$

A Escola de Frankfurt, desde os seus primeiros momentos, foi marcada pela teoria crítica de Adorno, cujo desdobramento último, mas de modo nenhum linear ou "necessário", possivelmente venha a ser a Teoria do agir comunicativo de Habermas.

Segundo MacCarney, ${ }^{21}$ Adorno é o representante paradigmático da doutrina da crítica social da Escola de Frankfurt. Seu postulado central consiste em afirmar que, para uma teoria ser dialética, tem necessariamente que ser imanente (17/19), no sentido de realizar a crítica do objeto do interior do próprio objeto. ${ }^{22}$ Assim, a crítica à sociedade burguesa deve ter como eixo o fato de esta sociedade não efetivar seus próprios valores. "Neste modelo, a crítica ima-

${ }^{20}$ LUKÁCS, G., Prefácio de 1967 à História e consciência de classe.

${ }^{21}$ MacCARNEY, J., Social theory and the crisis of marxism, Ed. Verso, Londres/Nova Iorque, 1990. Tanto quanto sabemos, o mais abrangente estudo acerca da evolução da Escola de Frankfurt é o de Martin Jay, La imaginación dialéctica (Ed. Taurus, Madrid, 1974). Todavia, nossa exposição se apoiará fundamentalmente em MacCarney. O estudo de Jay é feito do interior do pensamento frankfurtiano, de tal modo que as conexões e os aspectos do desenvolvimento da Escola de Frankfurt privilegiados se orientam por uma angulação - para ser breve - construída como que por uma auto-reflexão da Escola de Frankfurt. Isto confere ao estudo de Jay um caráter internamente fechado e sua utilização, nesse ensaio, implicaria em retrabalhar os elementos que ele fornece, exigindo um tempo que não temos disponível. Por isso, ainda que muito mais restritas, as indicações de MacCarney nos são mais úteis nesse momento. As citações serão feitas no corpo do texto, entre parênteses.

${ }^{22}$ Essa crítica em nada se aproxima de uma atitude "positivista". A nosso ver, a crítica do existente e a indicação de elementos para uma proposta de transformação da sociedade contemporânea se contrapõe frontalmente à prática positivista que recusa, por princípio, qualquer valoração do "dado". Nesse sentido, nos parece um exagero a aproximação entre a Teoria Crítica e o Positivismo como tentada por Balaban, O., "The positivist nature of the critical theory", in Science and Society, 53:4, 1989.

Temáticas, Campinas, 1(1/2):95-126, jul./dez. 1993. 
nente vive da distância entre o que a sociedade professa e o que ela realiza." (19)

A divergência com a postura marxiana é imediatamente perceptível: Marx nunca aceitou os limites da sociedade burguesa. como seu horizonte de crítica à ordem capitalista. Os problemas daí decorrentes, somados às dificuldades de conceber uma teoria burguesa crítica que não fosse conservadora, levou a Escola de Frankfurt a abandonar esta primeira postura teórica e adentrar na sua complexa e tortuosa evolução a qual, ao final, evidenciará a incapacidade da crítica imanente frankfurtiana dar conta da crítica radical e superadora da sociabilidade burguesa.

Ao final desse percurso, "A crítica imanente mais uma vez provou-se incapaz de fincar um pé na realidade." (41). O projeto de renovar a tradição marxista atola na areia (42). A saída parece 6er um abandono do campo marxista, e é neste sentido que se movimenta Habermas: com sua teoria do agir comunicativo termina por retornar a Kant (43).

\section{II.1 Habermas e a Centralidade do "Mundo da Vida"}

Em Para a reconstrução do materialismo histórico, ${ }^{23}$ argumenta Habermas que o trabalho não é a categoria fundante do ser social, pois esta categoria já se encontra presente nos primatas superiores e nos hominídeos. O que distingue o ser social da natureza, portanto, é a articulação do trabalho com a fala, esta sim uma exclusividade do ser social. Tal articulação é o fundamento do agir comunicativo, verdadeiro traço distintivo dos homens frente ao ser natural (116-7. Cf. tb. pp. 118 e 121), com o que a constituição da linguagem, de suas estruturas lógicas mais profundas, passa a ser o componente

${ }^{23}$ Este ensaio foi publicado no Brasil na coletânea intitulada Para a reconstrução do materialismo histórico, São Paulo, 2a edição, 1990. As citaçōes serão feitas no corpo do texto, entre parênteses.

Temáticas, Campinas, 1(1/2):95-126, jul./dez. 1993. 
fundamental do ser do homem. (14)

"o gênero aprende não só na dimensão (decisiva para o desenvolvimento das forças produtivas) do saber tecnicamente valorizável, mas também na dimensão (determinante para as estruturas de interação) da consciência prático-moral. As regras do agir comunicativo desenvolvem-se, certamente, em relação a mudanças no âmbito do agir instrumental e estratégico; mas ao fazê-lo, seguem uma lógica própria". (128)

A busca desta "lógica própria" das "estruturas da intersubjetividade produzidas lingüisticamente" orientou as pesquisas de Habermas nos anos imediatamente posteriores à publicação de Para $a$ reconstrução do materialismo histórico e terminou por conduzi-lo à Teoria do agir comunicativo.

Em Theorie des kommunikativen Handeln ${ }^{24}$ o interesse e o objetivo de Habermas é fundamentar as "ciências sociais em uma teoria da linguagem" (9).

Nessa démarche habermasiana, a "pretensão de validade" implícita em toda emissão comunicativa, pretensão esta que, por ser racional e para ser racional, necessariamente deve ser passível de crítica (24-6), tem por fundamento o fato de:

"Um juizo só pode ser objetivo se faz pela via de uma pretensão transubjetiva de validade que, para qualquer observador ou destinatário tenha o mesmo significado que para o sujeito agente. A verdade ou a eficácia são pretensões deste tipo."(26 - grifo meu)

Em poucas palavras, já que o mundo "apenas cobra objetividade pelo fato de ser reconhecido e considerado como um e o mesmo mundo por uma comunidade de sujeitos capazes de linguagem e de

${ }^{24}$ HABERMAS, J., Theorie des kommunikativen handelns. Suharkamp Verlag, Frankfurt, 1981. Nós utilizaremos a tradução espanhola Teoría de la acción comunicativa, Ed. Taurus, Madrid, 1987. As citaçōes serão feitas ao longo do texto entre parênteses.

Temáticas, Campinas, 1(1/2):95-126, jul./dez. 1993. 
ação", é a "prática comunicativa" que dá sustentação ao "conceito abstrato de mundo" ("mundo de vida") que torna possível a objetividade de um mundo. (30) Por sua vez, o mundo da vida "é delimitado pela totalidade das interpretações que são pressupostas pelos participantes como um saber de fundo". (31)

Para Habermas, portanto, é uma "pretensão transubjetiva de validade" que funda a "objetividade" de um mundo. E, na constituição dessa transubjetividade, é a esfera gnosiológica (o reconhecimento e a consideração subjetivos da validade objetiva de uma pretensão) o momento fundante. Isto conduz Habermas à análise da "prática comunicativa" que considera essencial à constituição da transubjetividade.

Através da análise da prática da argumentação, deduz Habermas que "o entendimento é imanente como o telos à linguagem humana" (369). Para explicar a ação comunicativa devemos recorrer ao entendimento; este tem por base conviç̧ões comuns que só podem surgir pela interação lingüística com intensão comunicativa, o que nos remete, de volta, à ação comunicativa! Saída de Habermas: buscar a distinção entre perlocução e ilocução de Austin para demonstrar esta ligação originária, primária, do entendimento enquanto telos da fala - de modo que todos os outros modos da fala seriam decorrências parasitárias deste modo originário (369-70).

Dada a limitação de espaço, não nos deteremos na discussão de Austin por Habermas. Dela nos é fundamental, no momento, apenas o fato de nela Habermas encontrar elementos para concluir que:

"A ação comunicativa se desenvolve dentro de um mundo da vida que permanece por trás dos participantes na comunicação. A estes apenas se lhes apresenta na forma préreflexiva de uns pressupostos de fundo que se dão por assegurados e de umas habilidades que se dominam sem se fazer problemas delas." (428-9)

É, pois, "nas estruturas implicitamente sabidas do mundo da vida (...)" (432) que devemos buscar o fundamento último da ação

Temáticas, Campinas, 1(1/2):95-126, jul./dez. 1993. 
comunicativa:

"O mundo da vida é, por assim dizer, o lugar transcendental em que o falante e o ouvinte se saem ao encontro; em que podem colocar-se reciprocamente a pretensão de que suas emissões concordam com o mundo (com o mundo objetivo, com o mundo social e com o mundo subjetivo); e que podem criticar e exibir os fundamentos dessas pretensões de validade, resolver seus desentendimentos e chegar a um acordo." (178-9)

A nosso ver, a debilidade fundamental do construto habermasiano estaria no fato de as articulações que permitiriam ao mundo da vida fundar a subjetividade não serem expostas, ainda que sejam afirmadas. Em um artigo recente,$^{25}$ Giannotti critica esta debilidade afirmando que:

"É toda uma concep̧̧ão de filosofia transcendental que está sendo posta em prática. (...) Habermas parte duma opinião neutra, sem ser asserida, embora pertencendo ao mundo da vida, opinião que sendo tematizada (isto só pode ser feito por um ato de consciência) transfere-se para a linguagem das descrições ponentes. Isto graças a diferenças meramente psicológicas, tais como clareza e certeza."

Esquece-se, Habermas, que

"para seguir uma regra não é suficiente que os atores façam acordos a respeito das definições, pois enquanto não souberem que todos estão entendendo as palavras da mesma maneira, não sabem ainda se empregarão as definições do mesmo modo. Além das definiçōes consentidas, ainda é preciso um acordo sobre seu uso". (20)

Em suma, a coloração neokantiana já perceptível em Para a reconstrução..., em Teoria do agir comunicativo ganha em densidade.

${ }^{25}$ Giannotti, J. A., "Habermas: mão e contramão", in Novos Estudos CEBRAP, 31, outubro 1991.

Temáticas, Campinas, 1(1/2):95-126, jul./dez. 1993. 
Como conclusão, vale apontar uma certa ironia. A Teoria do agir comunicativo é um dos desdobramentos lógicos possíveis, mas não necessário, da postulação inicial da crítica imanente por Adorno e Horkheimer. No universo kantiano, desde que as condições de conhecimento do objeto são fundamentadas na própria con'strução do objeto pela razão, a crítica racional do mesmo sempre será imanente. $^{26}$

Contudo, com esta solução, desaparece o projeto inicial da Escola de Frankfurt, o da crítica imanente tal como era proposta. Desapareceu, curiosamente, não pelo abandono dos pressupostos da crítica em si, mas pela mudança do estatuto ontológico do objeto. No primeiro momento, o objeto é hegelo-marxiano; agora, o objeto é de corte kantiano.

Em suma, o idealismo marxista se caracteriza:

1) pela incapacidade em articular, num mesmo sistema teórico, o caráter de continuidade marcante da ordem burguesa neste século com a crítica imanente ao capital;

2) pela crescente aproximação com o kantismo, nas suas mais variadas vertentes, à medida em que a evolução do projeto original da crítica imamente revela seus problemas internos;

3 ) conseqüentemente, por um questionamento da centralidade do trabalho enquanto categoria fundante do ser social e pelo abandono da determinabilidade da consciência pelo ser. A lógica própria do mundo dos homens se consubstanciaria, na sua essência, para além do trabalho (aqui tomado no sentido lukácsiano de protoforma da praxis social).

4) a crise do idealismo marxista se consubstancia no crescente e manifesto idealismo de suas formulações, terminando por se desdobrar no neokantismo do último Habermas. Crescentemente Marx e sua obra deixam de ser o referencial, para serem quando muito, um referencial entre outros. Sob o impacto das transformações das

${ }^{26}$ MacCarney, op. cit., p. 43.

Temáticas, Campinas, 1(1/2):95-126, jul./dez. 1993. 
últimas décadas, a trajetória desta vertente é cada vez mais "difusamente" marxista e cada vez mais nitidamente liberal. ${ }^{27}$

\section{O MARXISMO ONTOLÓGICo}

O marxismo ontológico é representado pela vertente Korsch, Gramsci, Lukács. Mantendo o materialismo (que neles se expressa pelo reconhecimento da antecedência do ser sobre a consciência, do predomínio da reprodução material na totalidade social), buscam resgatar a obra marxiana enquanto momento de constituição de uma "nova visão de mundo".

Em Korsch, ${ }^{28}$ os elementos teóricos constitutivos deste resgate estão ainda em forma germinal. Toda a sua discussão contra o mecanicismo e economicismo imperante na III Internacional, já na década de 1920 , teve como centro a postulação de que a "superação da filosofia" a que aludia Marx nas Teses Ad Feuerbach, apenas seria possível com a superação do mundo burguês. Visto de algumas décadas depois, o combate de Korsch ao marxismo enquanto ciência positivista de qualquer tipo, a reafirmação da herança hegeliana de Marx, e a luta pela categoria da totalidade enquanto central para o marxismo, são elementos que contribuíram para a constituição do marxismo ontológico.

${ }^{27}$ Há que se salientar que existem profundas diferenças no campo liberal. Nem todos os gatos são pardos. Todavia, no horizonte deste ensaio, não caberia uma discussão das particularidades do liberalismo de Habermas. Assinalaremos, portanto e tão somente, que a concepção de mundo, a weltanschauung, que permeia um escrito como "A Nova Intransparência a crise do Estado de Bem Estar e o esgotamento das energias utópicas", (Novos Estudos CEBRAP, $n^{\circ} \cdot 18$, set. 1987) é bem representativa do que consideramos ser o liberalismo habermasiano.

${ }^{28}$ Marxisme et philosophie, Paris, 1964, é a obra mais significativa da perspectiva por nós adotada.

Temáticas, Campinas, 1(1/2):95-126, jul./dez. 1993. 
Em Gramsci encontramos uma recusa cabal do mecanicismo e do economicismo do marxismo vulgar. Todavia, com um importante avanço em relação a Korsch: agora as questões ontológicas já se fazem explicitamente presentes, ainda que não sejam plenamente desenvolvidas. Exemplares são algumas passagens dos Cadernos do Cárcere $^{29}$ nas quais discute David Ricardo. Sua argumentação vai no sentido de que Ricardo, com a descoberta da lei do valor e da lei tendencial de queda da taxa de lucros, desvela o segredo de uma nova imanência, aquela constitutiva do ser social. Nesta nova imanência, as leis não teriam o caráter das leis físicas naturais, mas delimitariam tendências identificáveis a partir do desenvolvimento passado. A história, enquanto ciência, teria a tarefa de desvendar a legalidade do mundo dos homens, uma nova imanência frente à natureza.

\section{III.1 LuKÁcs E Para uma Ontologia do Ser Social}

As contribuições de Lukács ao desenvolvimento do marxismo ontológico nos parecem decisivas e a elas dedicaremos a parte final deste ensaio. São elas o momento privilegiado na constituição desta vertente do pensamento marxista contemporâneo.

Ainda que em Gramsci encontremos referências à esfera ontológica, é em Lukács que, pela primeira vez no marxismo, são explícita e detalhadamente abordados os aspectos decisivos da reflexão ontológica. Como sabemos, a problemática central em toda ontologia se condensa no tratamento dado à substancialidade. Os traços ontológicos da substancialidade são os responsáveis pela ancoragem das respostas alcançadas, que devem ser de tal modo resolutivas, a não exigirem um outro "porquê". A radicalidade da compreensão do real aberta por cada ontologia tem na categoria da substância seu problema decisivo.

${ }^{29}$ GRAMSCI, A., Quaderni del Carcere, Einaudi Editori, Torino 1975, pg. 1247 e 1477.

Temáticas, Campinas, 1(1/2):95-126, jul./dez. 1993. 
É este o ponto de partida de Lukács: Marx teria descoberto e delineado uma nova concepção da substancialidade do mundo dos homens; este seria absolutamente histórico e social.

Por histórico, Lukács concebe, após Marx, uma substância cuja essência nem é dada a priori (como em Hegel ou S. Tomás de Aquino), nem é mera decorrência do desenvolvimento geral do ser. Pelo contrário: a substância é histórica porque ela se consubstancia ao longo do seu processo de desenvolvimento concreto. A essência, neste sentido, é o complexo de determinaçōes que permanece ao longo do seu desdobramento categorial. Em outras palavras, a essencialidade da substância são os traços ontológicos mais profundos que constituem seus elementos de continuidade. ${ }^{30}$

Por social, Lukács, após Marx, concebe uma substancialidade do mundo dos homens que é resultado exclusivo da ação e pensamento dos homens, enquanto indivíduos e enquanto gênero humano. Isto significa que os homens fazem a sua história e que este fazer a história não encontra em nenhuma instância - "natural" ou não - qualquer limite para o seu desenvolvimento. Os homens são os senhores absolutos do seu destino. Não há, pois, qualquer possibilidade em buscar, na natureza, uma essência fixa como referencial para a valoração e crítica da sociabilidade capitalista.

Assinalar que os homens são senhores absolutos de sua história não se opõe, em Lukács, ao reconhecimento que "a tradição de todas as gerações mortas oprime como um pesadelo o cérebro dos vivos" ${ }^{31}$ $\mathrm{E}$ que, por isso, os homens constroem o seu destino num hic et nunc historicamente determinado, que impõe necessidades e delineia o campo de possibilidades para que esta construção se dê. $\mathrm{O}$ caráter de pura sociabilidade do mundo dos homens, em Lukács, não significa, em absoluto, nem a contraposição antinômica entre necessidade

${ }^{30}$ Cf. LUKÁCS, G., Per una ontologia dell'essere sociale. Ed. Riuniti, Roma, 1976 e 1981, vol II*, pp. 106, 319-20.

${ }^{31}$ Marx, K., "18 Brumário de Luis Bonaparte", in Textos, vol III, São Paulo 1977, p. 203.

Temáticas, Campinas, 1(1/2):95-126, jul./dez. 1993. 
e liberdade, nem muito menos a mecânica prevalência de qualquer um destes termos sobre o outro. $\mathrm{Na}$ análise deste complexo problemático há que se reconhecer acima de tudo que, tanto a categoria da liberdade como a categoria da necessidade ${ }^{32}$ são socialmente construídas, ou seja, apenas podem surgir e se desdobrar pela mediação cotidiana de atos teleologicamente postos pelos indivíduos no processo de reprodução social.

De modo análogo, reconhecer o caráter puramente sócio-humano do ser social não conduz Lukács a postular o desaparecimento da natureza. Antes de mais nada, porque tanto os atos singulares teleologicamente postos (no pólo da singularidade individual), assim como a reprodução social global (no pólo da generidade, da universalidade humana), apenas podem surgir e se desdobrar categorialmente em contínua e ineliminável troca orgânica com a natureza, via trabalho. São dois os traços ontológicos fundamentais dessa troca orgânica: por um lado, há uma ruptura ontológica entre a reprodução social e a processualidade natural, ruptura cuja essência é a possibilidade de um ser-para-si no mundo dos homens impossível para a natureza. Por outro lado, a troca orgânica entre o gênero humano e a natureza implica na incessante transformação do mundo natural em um mundo social. Cada vez com maiores intensidade e escala, a natureza passa por processos de objetivação que conferem uma forma e um conteúdo puramente sociais, que apenas enquanto objetivaçōes de prévias-ideações poderiam surgir e se desenvolver. Contudo, de modo algum, a gênese e o desenvolvimento da esfera ontológica representada pelo mundo dos homens implicam no desaparecimento da natureza enquanto uma esfera ontológica distinta do ser social, nem sequer como uma possibilidade a mais remota. Para ser brevíssimo, a madeira do cabo de um machado continua a ser madeira.

${ }^{32}$ Nos referimos aqui, obviamente, à necessidade social. Que a natureza apresenta uma necessidade dada pela própria legalidade natural, que não é socialmente construída, é um aspecto fundamental da ontologia lukácsiana.

Temáticas, Campinas, 1(1/2):95-126, jul./dez. 1993. 
Lukács traça um tertium datur entre aquelas posiçōes que, de um lado, postulam a mera continuidade entre natureza e ser social (alguns momentos do marxismo vulgar, por exemplo) ou, então, que postulam a completa dissociação entre elas: o ser social é, ontologicamente distinto da natureza, mas esta distinção apenas pode surgir e se desenvolver numa complexa articulação com o mundo natural, pela qual este último é constantemente submetido a transformações teleologicamente orientadas.

Da perspectiva de Lukács, portanto, buscar na natureza biológica do homem um referencial fixo que permita a crítica do estranhamento capitalista - está fadada ao insucesso. Ontologicamente, como ser social e natureza são esferas distintas, não há como encontrar na processualidade natural o fundamento de ser de um fenômeno puramente social, como é o estranhamento. Fazê-lo implicará ou em conferir uma legalidade natural ao mundo dos homens, ou então reduzir a legalidade social às leis da natureza. Em ambos os casos, segundo Lukács, está perdida a possibilidade de construção de uma ontologia que reconheça o ser social na sua simultânea conexão e radical diferenciação do mundo natural.

Destes pressupostos ontológicos mais gerais, Lukács retira conclusões que nos parecem de extrema valia para as discussões que se travam no interior do marxismo hoje. Inicia ele por afirmar que a especificidade ontológica do mundo dos homens frente à natureza é que, no ser social, a substancialidade é causalidade posta. Uma cadeira não é o material (ferro, madeira, etc.) de que é feita, mas sim este material organizado segundo uma lógica-ontológica que apenas pode ser posta através de uma ação teleologicamente orientada, ou seja, através de um ato de trabalho humano.

A teleologia, portanto, na esfera social (e apenas nela) é uma "categoria ontológica objetiva", ${ }^{33}$ existe como instância capaz de ordenar o real de modo a criar entes e relações anteriormente inexistentes, ontologicamente novos. Estes novos entes e relações não

${ }^{33}$ LUKÁCS, G., Per una ontologia..., op. cit., vol II*, pg. 20.

Temáticas, Campinas, 1(1/2):95-126, jul./dez. 1993. 
poderiam vir a ser senão pela modificação teleologicamente orientada da materialidade anteriormente existente.

Todavia, não menos verdadeiro, segundo Lukács, é que esta nova materialidade, esta nova esfera ontológica - o mundo dos homens - é um mundo objetivo distinto da subjetividade que operou a teleologia inerente a toda transformação do existente pelos homens. A cadeira tem efetivamente uma história distinta da história do seu criador, e esta autonomia da história do objetivado em relação à consciência que o criou é um elemento ontologicamente ineliminável na relação entre o hómem e o mundo dos homens, entre a prévia-ideação e o objeto posto pelo ato de objetivação que é o trabalho.

Em poucas palavras, a estrutura do trabalho comporta, concomitantemente ao processo de objetivação (que consubstancia em um objeto concreto a ideação prévia e abstratamente construída), o momento da alienação, (pelo qual o objeto construído se consubstancia em um ente ontologicamente distinto do sujeito e da consciência deste sujeito) que operou o ato teleologicamente orientado que está na sua gênese.

Esta distinção ontológica consubstanciada pela alienação no interior do trabalho é o fundamento ontológico último da possibilidade das complexas determinações reflexivas que se desdobram entre o objeto e seu criador, entre o mundo material e a consciência, entre a totalidade social e as individualidades, etc. $\mathrm{Na}$ ontologia lukácsiana, em definitivo, não há qualquer lugar para a identidade sujeito-objeto. Ao contrário de Hegel, a alienação é um momento da construção genérica do ser social (tanto no pólo da sua totalidade como no pólo das individualidades), e por isso um traço ontológico ineliminável.

Com isto, Lukács supera as antinomias que surgem tanto ao se identificar Hegel e Marx, como ao se construir um intransponível fosso entre os dois. Identificar formalmente classe operária e absoluto hegeliano, o tempo hegeliano com o tempo da luta de classes, a

Temáticas, Campinas, 1(1/2):95-126, jul./dez. 1993. 
relação sujeito-objeto mediada pelo trabalho em Marx com a apreensão do espírito do seu em-si no processo de construção do Espírito Absoluto, é, aos olhos de Lukács, desconhecer a ruptura ontológica que distingue e articula Marx e Hegel. Desconhecer os elementos de continuidade que articulam os dois pensadores, por outro lado, será novamente incorrer nos mais graves equívocos do marxismo vulgar. ${ }^{34}$

A distinção e concomitante articulação, posta pelo momento da alienação, entre o sujeito e o mundo objetivo, a distinção ontológica entre ente objetivado e consciência que operou a prévia ideação é o fundamento último para que, a essência do processo de sociabilização desdobre um complexo processo de generalização. Na esfera da subjetividade, este processo articula, num movimento constante, o conhecimento do singular com as generalizaçōes teóricas mais universais, o passado com o presente e o futuro, as tarefas que surgem no instante presente com a concepção de mundo.

No plano da objetividade, este processo de generalização insere cada objeto criado numa malha de relações e determinações que compõe a particularidade de cada momento histórico. De tal modo que a história deste objeto apenas pode se desdobrar qua história deste objeto singular, enquanto momento da história universal da humanidade. Por sua vez, a história humano-universal apenas pode se desdobrar enquanto tal na medida em que incorporar ao seu ser as determinações (não importa quão modestas) que emanam da particularidade da história do objeto criado. Novamente: não há qualquer identidade sujeito-objeto em Lukács, ainda que a subjeti-

${ }^{34} \mathrm{~A}$ convivência de Lukács com Hegel é muito rica. Se inicia antes mesmo do nosso filósofo ter se tornado marxista, e o acompanha em todas as suas fases, num permanente e apaixonante diálogo. Não é à toa, por isso, que o capítulo dedicado a Hegel, na Ontologia, é possivelmente o mais belo, com uma riqueza e uma plasticidade interna que, a nosso ver, apenas é comparável ao capítulo dedicado ao trabalho. Sua tese central, a da existência de uma dupla ontologia que perpassaria o sistema hegeliano é uma contribuição significativa ao estudo do filósofo alemão no nosso século.

Temáticas, Campinas, 1(1/2):95-126, jul./dez. 1993. 
vidade apenas possa existir em determinação reflexiva com o mundo material. ${ }^{35}$ Deste modo, numa processualidade que Lukács explora em detalhes no estudo da reprodução social, ao construir um objeto o indivíduo se constrói enquanto individualidade partícipe da generalidade humana.

No plano ontológico mais geral, singularidade, particularidade e universalidade são distintas categorias da processualidade social igualmente reais, com o mesmo estatuto de ser. ${ }^{36}$ De modo que a emancipação humana, a plena explicitação da generalidade humana, que com absoluta necessidade requer a supressão da estranhada esfera do individualismo burguês, apenas pode se dar com algo que vai para muito além da simples manutenção da esfera da particularidade, dos indivíduos. Esta esfera, em si própria, é tão ineliminável como as esferas da singularidade e da universalidade. A emancipação humana, portanto, para além da simples manutenção da individualidade humana, requer com absoluta necessidade, a mais completa explicitação das esferas da singularidade e da particularidade, o mais completo desenvolvimento das individualidades. Em Lukács, não há qualquer atenuação, por menor que seja, da importância da individualidade para a construção do gênero humano.

${ }^{35}$ Não há em Marx, segundo Lukács, qualquer identidade entre ser $\mathrm{e}$ valores morais e éticos, mas apenas uma complexa relação entre a materialidade sócio-historicamente construida e os valores que são objetiva e subjetivamente construidos nesse processo. Em poucas palavras, os valores são resultantes do complexo processo de generalização objetiva e subjetiva que funda a reprodução social e tão-só nesta simultânea conexão e distinção do ser-precisamente-assim existente desdobram a sua existência concreta.

${ }^{36}$ Novamente, nos referimos apenas ao ser social, sem com isso querer sugerir que estas categorias não existam, também - ainda que em uma moldura ontológica distinta - na natureza. Todavia, para evitar equívocos de qualquer tipo, faz-se necessário assinalar que o reconhecimento da existência de categorias ontológicas na natureza em nada aproxima Lukács do intento engelsiano expresso na Dialética da natureza. Muito pelo contrário, as críticas de Lukács àquelas posições de Engels são as mais radicais.

Temáticas, Campinas, 1(1/2):95-126, jul./dez. 1993. 
Do mesmo modo, não há qualquer elemento, por mais difuso, de uma concepção do ser social que se aproxime do indivíduo-mônada do liberalismo clássico ou do marxismo analítico. Por esta mesma razão, a plena explicitação da generidade, da universalidade socialmente construída, não implica no fim da história. Não há absoluto que hegelianamente supere, na sua constituição genérica, as esferas da singularidade e da particularidade.

$O$ processo de generalização subjetiva e objetiva a que nos referimos acima remete o ser social para além da esfera do trabalho. Ao generalizar subjetivamente, por exemplo, dá origem a conhecimentos e a processo de valoração que em nada se relacionam, a não ser muito mediadamente, com os atos de trabalho enquanto tal. Objetivamente, dão origem a relações e categorias sociais que apenas mediadamente se articulam com a transformação direta da natureza. Não podemos aqui, nem minimamente, nos alongarmos na discussão dessas mediaçōes em Lukács. Apenas fazemos estas considerações para demonstrar como, no interior da ontologia lukácsiana, é impossível a identidade entre os atos de trabalho e todos os atos sociais. Entre a esfera do trabalho e a construção da generidade humana se desdobra uma relação de identidade da identidade e da não-identidade: o trabalho dá origem a novas necessidades e a novas possibilidades para o desenvolvimento humano que não mais se identificam com ele. Do mesmo modo, a continuidade dos atos de trabalho requer que sejam atendidas necessidades sociais que não mais se referem diretamente ao trabalho enquanto tal. Pensemos em complexos sociais como a Ideologia, a Política, a Filosofia, a Estética, a Ética, etc., os quais, a partir de um dado patamar de desenvolvimento da sociabilidade, se tornam imprescindíveis para a organização e execução do trabalho, ainda que com este se relacionem por meio de mediações mais ou menos numerosas. Entre o trabalho e a totalidade social se interpõe, de modo cada vez mais nítido com o desenvolvimento das sociedades, uma esfera peculiar de mediaçōes que compõe a categoria social da reproduçāo.

Temáticas, Campinas, 1(1/2):95-126, jul./dez. 1993. 
Em comparação com as indicações de Gramsci, nos parece que o esforço lukácsiano apresenta uma contribuição fundamental. Ao contrário do que ocorre com o pensador italiano, a exploração em detalhes das conexões ontológicas que conectam tanto a subjetividade e a materialidade, como a individualidade e a totalidade social permite a Lukács introduzir importantes elementos na análise destas relaçōes. Não podemos, agora, nos deter na exposição destas conexões, e por isso apenas assinalaremos que, tanto na consubstanciação da individualidade, quanto na da totalidade social, o processo de generalização ao qual nos referimos acima compõe os seus nódulos mais essenciais.

Em suma, o marxismo ontológico se caracterizaria por:

1) chamar para o terreno da ontologia a resolução das questões decisivas ao marxismo contemporâneo. Por ontologia os autores compreendem desde um retorno à metafísica (Gould), a busca de uma essência humana imutável (MacCarney), até as determinações mais gerais do existente (Tertulian, Mészáros).

2) considerar, coerentemente, os atos humanos enquanto elementos ontologicamente constitutivos do ser social. A essência de tais atos, é a construção processual da sociabilidade humana pelo trabalho;

3) manter os postulados centrais de Marx: os homens fazem sua própria história, mas em circunstâncias que não escolheram; a prioridade da matéria sobre a consciência, e da reprodução material sobre a totalidade social; a necessidade do socialismo enquanto momento privilegiado da emancipação humana, etc.;

4) argumentar, com muitos matizes e diferenças, que a herança hegeliana de Marx não deve ser esquecida, ao lado da afirmação da ruptura, que cada um divisa a seu modo, entre os dois pensadores.

Temáticas, Campinas, 1(1/2):95-126, jul./dez. 1993. 


\section{Conclusão}

Depois do que foi dito, é evidente que a concepção da substancialidade humana enquanto subjetividade objetivada representa uma ruptura radical com as duas outras principais vertentes do marxismo neste século.

Rompe com o marxismo estruturalista ao integrar a subjetividade humana enquanto elemento ontologicamente fundamental ao mundo dos homens. A teleologia do trabalho é uma "categoria ontológica objetiva" na consubstanciação desta nova forma de ser; as categorias sociais apenas podem surgir (e se desdobrar) em processualidades historicamente concretas em determinação reflexiva com a objetivação de novas posições teleológicas. Com isto, as antinomias entre materialidade e espírito, entre ser-precisamente-assim existente e consciência, que compõem o campo de maiores dificuldades teóricas para o marxismo estruturalista, podem ser tratadas em um novo "campo teórico". Podemos abandonar as investigações lógico-abstratas como aquelas que encontramos em Althusser, onde o "pensamento" se transforma, ao mesmo tempo, em algo tão distinto do real que apenas pode se referir a "objetos do conhecimento" e em um "modo de produção" de idéias determinado pelo real.

Em outras palavras, se a concepção ontológica de fundo que encontramos no marxismo estruturalista, com todas as diferenças existentes no interior deste campo, tem como elemento central uma tal antinomia espírito-matéria, não é nada surpreendente que esta vertente, ao buscar as soluções de problemas que não pode tratar, como seria apropriado, no terreno ontológico, termine em um beco sem saída na esfera gnosiológica. Expressões desse beco sem saída em que se colocou o marxismo estruturalista, a nosso ver, são tanto a démarche althusseriana que termina por postular uma subjetividade que não é pensamento, um pensamento que não é subjetividade e um objeto que não é o ser-precisamente-assim existente; como a oposição material/social característica de Cohen.

Temáticas, Campinas, 1(1/2):95-126, jul./dez. 1993. 
Os problemas enfrentados pelo marxismo estruturalista se desdobram, também, em uma outra dimensão: a relação indivíduo/sociedade. Se, num primeiro momento, o indivíduo é mero suporte (Träger) das determinações infraestruturajs, com o marxismo analítico ele se transforma em uma individualidade-mônada portadora das regras mais gerais das situações de jogos. $\mathrm{O}$ que nos interessa salientar, desconsiderando diferenças significativas, é o fato que tanto Althusser como o marxismo analítico, passando por Cohen, constroem modelos teóricos com uma explícita fundação não-ontológica, incapazes de trabalhar a totalidade social em sua complexa unitariedade.

Com o abandono da categoria da totalidade, e a conseqüente fragmentação do mundo dos homens, abre-se o terreno que alicerça as teorizações, típicas do marxismo analítico, que justificam a exploração do homem pelo homem pela mediação do mercado com o argumento de que este seria o melhor dos mundos possíveis.

A ontologia de Lukács rompe com o idealismo marxista por manter a determinação da consciência pelo ser, e ao reafirmar a predominância da reprodução material sobre a totalidade social. No entanto, concebe estas relações como determinações reflexivas. $\mathrm{Ou}$ seja, o predomínio ontológico da esfera produtiva sobre a totalidade social apenas pode se dar por meio da objetivação cotidiana de infinitos atos concretos teleologicamente postos.

Estes atos, por sua vez, frente às pressões e demandas postas pela dinâmica reprodutiva da formação social em que estão inseridos, têm sempre um caráter de alternativa, de escolha. De modo que a predominância da esfera econômica sobre a totalidade social tem como mediação ineliminável a cotidianidade com suas múltiplas e variáveis determinações. $\mathrm{O}$ que faz com que esta predominância possa ser tudo, menos mecânica, imediata.

Isto, também, faz com que não se possa determinar a priori uma forma abstrata e logicamente fixada de modelo genérico desta predominância. A cada momento esta predominância se afirma

Temáticas, Campinas, 1(1/2):95-126, jul./dez. 1993. 
de uma maneira distinta, o que pode incluir, momentaneamente, até mesmo a sua aparente negação: uma radical alteração da esfera econômica pela ação de uma esfera específica da praxis social, como ocorre nos momentos revolucionários.

Metodologicamente, as possibilidades resolutivas são enormes, pois rompe com a relação de exterioridade entre o sujeito e o objeto sem cair na identidade absoluta de um com o outro. Nem Feuerbach nem Hegel: temos aqui um legítimo tertium datur. $O$ objeto é portador de suas determinações ontológicas específicas, e é ele que comporá o campo resolutivo do grau de veracidade de uma teoria. ${ }^{37}$ Todavia, este objeto nem é estático nem deixa de ser, em algum grau, causalidade posta. Portanto, é o campo da objetividade que coloca as demandas metodológicas necessárias à sua apreensão pela subjetividade, não existindo por isso nenhuma questão metodológica que possa ter sua resolução a priori no campo mais abstrato da lógica e do rigor meramente formal. Esta postura também se distingue radicalmente do empirismo e do positivismo ao considerar o objeto como histórico. Mesmo a natureza mais pura, neste sentido, se constitui enquanto objeto ao longo da história, sem que isto em nada diminua sua objetividade ontológica primária.

As investigaçōes lukácsianas parecem apontar para o fato de que, no interior da tradição marxiana, nem o materialismo (a determinação da consciência pelo ser) nem a dialética (movimento do real enquanto complexo de complexos) estão esgotados. Isto, todavia, não significa desconhecer que graves problemas não tiveram sua resolução delineada, nem sequer nos termos mais gerais, pelo

${ }^{37}$ Apenas formalmente temos aqui alguma semelhança com a critica imanente proposta por Adorno: a crítica do objeto do seu próprio interior. A moldura ontológica distinta confere à imanência da crítica em Lukács, e na Escola de Frankfurt, um sentido bastante diverso. Enquanto nesta, a crítica se fundava na distância entre o que o objeto "prometia" e o que ele de fato realizava, em Lukács a verdadeira crítica imanente não pode deixar de desconsiderar as efetivas articulações que se interpõem entre cada objeto e a totalidade da história do gênero humano.

Temáticas, Campinas, 1(1/2):95-126, jul./dez. 1993. 
filósofo húngaro. Contudo, delimitar com um mínimo de rigor as possíveis insuficiências da investigação ontológica de Lukács é uma empreitada que se situa para além dos limites que nos propusemos ao iniciar a redação deste ensaio.

Terminaremos, por isso, chamando a atenção para um possível paradoxo.

$\mathrm{Na}$ constituição do materialismo ontológico, Gramsci e Lukács jogaram os papéis centrais. A crítica ao stalinismo, no plano teóricofilosófico, é radical nos dois pensadores. Todavia, tanto um como o outro se alinharam, de algum modo, com as posições políticas que respaldavam o marxismo estruturalista, quando não o marxismo mais vulgar. É no interior do duplo cerco representado pela prisão fascista, e pelo combate às suas idéias pela burocracia do Estado Soviético e da III Internacional, que Gramsci tem a genial antecipaçāo da redescoberta da obra marxiana enquanto fundação de uma nova ontologia. Analogamente, é no interior de um duplo cerceamento - posto pela opção de resistir no interior do bloco soviético - representado pela censura oficial, e pelo-constrangimento teóricopessoal oriundo da crença de que no bloco soviético se construía o socialismo (ainda que com desvios), é que Lukács elabora a sua crítica ao idealismo marxista e ao materialismo vulgar-mecanicista. Não deixa de ser irônico (a história tem a sua astúcią) que do interior do mais brutal cerco à atividade intelectual que nosso século conheceu tenha brotado uma corrente teórica tão fértil e promissora.

Em suma, apesar de possíveis lacunas e de questões deixadas em aberto, a ontologia lukácsiana nos parece a linha possível, nos dias de hoje, de defesa e de desenvolvimento dos elementos centrais da Weltanschauung marxiana: a objetividade ontológico-primária do ser e a radical historicidade e sociabilidade do mundo dos homens.

Temáticas, Campinas, 1(1/2):95-126, jul./dez. 1993. 